\title{
Design theory: history, state of the art and advancements
}

\author{
Pascal Le Masson · Kees Dorst • \\ Eswaran Subrahmanian
}

Published online: 21 March 2013

(c) Springer-Verlag London 2013

Over the last few years there have been important efforts to improve the rigor, unity and operationality of Design theories. This work builds on the multiple (but scattered) theoretical proposals in recent decades: General Design Theory and Axiomatic Design in the 80s, Coupled Design Process in the 90s, Infused Design and C-K Theory in the 2000s. These theories echoed issues in practices (e.g., new design tools, innovative design) and the advancements of other sciences (e.g., artificial intelligence, set theory, engineering sciences). They contributed to ground a research community that has been reinvigorated by several initiatives. ${ }^{1}$ Parallel to this effort, design theory is being debated in other disciplines such as information systems, management studies and industrial design following the flourishing of design thinking in these areas. This special issue was launched to gain better understanding of the early efforts in design theory, as well as showcasing promising contemporary research in design theory.

A public call for papers (CFP) was published that attracted 19 submissions ranging from various aspects of

P. Le Masson ( $\square)$

MINES ParisTech, 60 Boulevard Saint Michel,

75006 Paris, France

e-mail: pascal.le_masson@mines-paristech.fr

K. Dorst

University of Technology, Sydney,

PO Box 123, Broadway, NSW 2007, Australia

K. Dorst

Eindhoven University of Technology,

PO Box 513, 5600 MB Eindhoven, The Netherlands

E. Subrahmanian

Carnegie Mellon University, 5000 Forbes Ave,

Pittsburgh, PA 15213, USA

e-mail: sub@cmu.edu design methods to values in engineering design including those addressed design theory directly. After an extensive review process we choose those papers that addressed directly Design theory as their primary object of inquiry. Submissions were handled by the guest editors and submissions whose authors were guest editors were handled directly by the journal Editor-in-Chief. Recommendations of the guest editors passed through the Editor-in-Chief to make sure that the stringent standards of the journal are enforced on the special issue. Six papers have been accepted following this review process.

Of course such an issue cannot be exhaustive_-it should be seen as a first attempt, to be followed and augmented by other publications. Nevertheless, the critical ambition of this issue is to better identify the object of design theory and to begin to overcome shortcomings of their current conceptions.

\section{Design theory: a demanding research field}

Design theory is a very demanding research field. Design is an incredibly complex and sophisticated human activity that goes beyond animal design [see Orang Utan Nest Building;-_(van Casteren et al. 2012)] and "unselfconscious design" (Alexander 1964). Self conscious design contains many well-known activities such as decision making, optimization, modeling, knowledge production, prototyping, ideation, or evaluation. However, it cannot be reduced to any one of them or all of these activities (e.g., decisions are made in design, but design is more than decision making). Thus, design theory is not about modeling everything

\footnotetext{
${ }^{1}$ See in particular the special interest group on design theory, launched in 2008 on the suggestion of the Management Board of the Design Society.
} 
that one can find in a design practice, its goal is to precisely address issues that are beyond the scope of the classical models that accompany its constituent activities (decision making, prescriptive models, hypothetic-deductive model and others). The questions this goal raises are of course: What, then, are the core phenomena of Design? Is Design driven by novelty, continuous improvement, creativity, or imagination?

Design theorists realized that we cannot expect to answer these questions with ordinary language, and that this investigation will thus require high level formal languages and models. This is an ongoing quest: many issues remain in the elaboration of these fledgling models, and their validity and veracity are under critical scrutiny. In February 2013, at the 6th Paris Workshop of the Design Theory SIG of the Design Society, Armand Hatchuel and Yoram Reich made a synthesis of 5 years of works of the SIG and mentioned four main difficulties for research on Design Theory:

1. no self evident unity of the design theory field,

2. multiple paradigm shifts that threaten the specificity of design,

3. the fragmentation of the design professions and,

4. the limits of empirical research.

The lead questions in this editorial are: how did the papers presented in this special issue deal with these difficulties? And how do they open new paths for research in design theory? We first elaborate and detail these four challenges before formulating our perspective on the papers.

\subsection{No self-evident unity of the design theory field}

There are already many models for design theories. For design theories might be as old as (self conscious) design itself. As early as $20 \mathrm{BC}$, in his De Architectura Vitruvius proposed an abstract definition of architecture that helped the architects to deal with the variety of knowledge and go beyond the specificity of each building-architecture "depends on Order, Arrangement, Eurhythmy, Symmetry, Propriety, and Economy" (book 1, Chap. 2). Following the rapid development of Mechanical engineering in the nineteenth century, the recognition of Design theories as crucial tools led to help teach machine design and to organize design work in industry. Then, as the scope of engineering sciences increased very rapidly, each engineering revolution (e.g., chemical, electrical, electronics, or software) was accompanied by the development of its own appropriate design tools and theories. It is primarily after WW2 that the idea of a Design theory that would be common to architecture and engineering disciplines emerged. Following the Vitruvius approach, one of the earliest drive at systematizing design was undertaken in the first conference on Systematic Design Methods in 1960s as in the method of analysis, synthesis and evaluation (ASE) (Jones and Thornley 1963). These efforts were further elaborated as theory of technical systems (Hubka and Eder 1988) and its more recent advances, FBS (Gero 1990; Dorst and Vermaas 2005), General Design Theory (Yoshikawa 1981; Reich 1995), Axiomatic Design (Suh 1990), Coupled Design Process (Braha and Reich 2003), Infused Design (Shai and Reich 2004) or C-K theory (Hatchuel and Weil 2009). But if one looks beyond the similarities in these domain-independent theories, are they complementary or perhaps contradictory? Do they share common roots? To what extent are the theories limited by the (implicit) goals that motivated their creation? Are they reasonably comprehensive in their approach to design? These questions remain open and critical.

\subsection{Multiple paradigm shifts that threat the specificity} of design

Moreover, the efforts towards unity of the field are continuously shaken by changing paradigms in the analysis of design. In the 1960s-1970s, the temptation was to assimilate design to decision science, cybernetics and information theory-one major attempt was made by Simon. This resulted in his "sciences of the artificial" that was rooted in the concept of a general problem solver (Simon 1969). During the 70 s- 80 s there was a move towards creating a universal design method that was akin to the scientific method (Cross 1984). Overlapping with this move, in 1980s-1990s Artificial Intelligence (more generally computational models of design), Computer Aided Design systems and Systems theory were meant to be the core of design theory. ${ }^{2}$ In 1990s-2000s situated cognition, communication and agent-based systems were the new potential roots for design theory; and today advances in neuroscience threaten to overwhelm design theory. The strength and health of the design theory appears in the capacity of researchers to show how design theory can learn from all these approaches, proposing integrated models that go beyond these paradigms and offer a rigorous, meaningful and autonomous corpus that fits the nature of design. For instance it was underlined and demonstrated that design was more than "decision making", even if a "bounded rational choice" (Hatchuel 2002; Dorst 2006), and this critic led to propose that design was rather an "expandable rationality" (Hatchuel 2002). The papers of this special issue show that this autonomous, rigorous corpus has grown over time and is now forming a basis to dialog with other disciplines-mathematics, logics, engineering sciences and cognition.

\footnotetext{
${ }^{2}$ For comprehensive map of design methods and theories as of 1992 see (Konda et al. 1992).
} 


\subsection{The fragmentation of design professions}

Surprisingly, design professionals are not the ones leading the effort to create a disciplinary foundation. In spite for efforts of by design research societies ${ }^{3}$ to bring them together through a joint conference, efforts in design theory are still fragmented. The contrasted figures of architects, engineers and industrial designers use different journals, rely on different epistemologies, and connect to different disciplines. This presents a huge challenge for design theory: how to overcome the professional traditions to uncover the universality of design.

Beyond the scientific issue, this is also an important social and political issue: showing the universality of design leads also to reveal its presence today in all aspects of social, organizational and political life, where decision making more and more appears secondary and determined by the critical issue of generating the set of alternatives and organizing the investigations to expand it.

\subsection{The limits of empirical research}

Finally, design theory has to overcome a fourth obstacle that focuses on empirical research and its contribution to design theory. Empirical research is necessary for design theory.For example to test hypotheses or to suggest new phenomena to be modeled. There has always been strong relationships between empirical and theoretical approaches in design theory-with complex interdependences, as suggested by the models of design processes of (Finger and Dixon 1989) or by the historical analysis of pendulum movements between "art" and "science" in design methods (Heymann 2005). More recently, many empirical approaches have been used in the community (in the US and in Europe). As shown in (Heymann 2005) or (Ehrlenspiel 1995), they led to enriching the phenomenology of collective design. A sample of the range and focus of empirical studies in design from studying the design process to supporting design process across can be seen in (Subrahmanian et al. 2004). But on the whole these studies do not address the problem of a formal theoretical unity. One of the challenges of design theory today consists in providing formal frameworks that lead to testable hypothesis, and to build the relevant instruments (protocols, observation techniques, tasks analysis and others) to empirically analyze design practices at this fundamental level. Research in design theory should be anchored in an interplay between formal models and empirical studies.

\footnotetext{
3 The conference held every year by International Association of Design Research Societies (IASDR) is an attempt to bring these efforts together including the Design society.
}

\section{Consolidating research on design theory}

In a nutshell, these are the four challenges to be overcome by the papers in this special issue: How did the papers travel this complex territory?

\subsection{Relating design theories to each other}

Many of the papers of the special issue study multiple design theories and compare them (e.g., Parameter Analysis and systematic design in Kroll, C-K theory and forcing in Hatchuel et al., C-K theory and Infused Design in Shai et al., C-K and systematic Design in Le Masson and Weil). These comparisons can be fruitful:

(a) they reveal hidden aspects and critical issues for design theory: the logic of "holes" in knowledge as departure point for design (Shai et al.), the logic of unknown to be differentiated from the logic of the known (Le Masson and Weil), and more generally, the elements of an ontology of design (Hatchuel et al.).

(b) these comparisons underline the interest of powerful formal design theories to analyze specific models and methods, helping to characterize their efficiency and limits. For instance, Le Masson and Weil's paper underlines that systematic design is relevant for rule-based design situations, Shai et al. illustrate the potential of infused design when knowledge is highly structured and connected, Kroll shows that Parameter Analysis has a strong value when designers want to renew design rules. These results pave the way to a contingent approach in design theory, to an understanding of the "ecology of theories and methods".

2.2 Overcoming paradigms that shade the specificity of design

Constructivism in design (Kazakçi), engineering science and design (Le Masson and Weil), creativity and scientific discovery (Kroll), ideation (Taura and Nagai), combinatorics (Hatchuel et al., Kroll) are discussed in this special issue.

(a) The discussion of these paradigms brings out the specificity of design. In Kroll, Le Masson and Weil, and Shai et al. we understand that design is more than engineering science. Taura and Nagai and Shai et al. demonstrate that design is more than ideation and creativity. We glean from Kazakçi, design as more than constructivism and in Taura and Nagai, Hatchuel 
et al. and Le Masson and Weil that it is more than combinatorics.

(b) Moreover it helps to enrich the paradigms themselves: Kazakçi proposes an extended view of constructivism, imaginative constructivism, Taura and Nagai a concept generation process relying on "dissimilarity recognition", Kroll, Shai et al., Le Masson and Weil and Hatchuel et al. focus on understanding how the dynamics of engineering sciences is based on design reasoning.

\subsection{Bridging the gap between professions}

The papers in the special issues dialog with multiple disciplines: with intuitionist mathematics (Kazakçi), with set theory (Hatchuel et al.), with orders in science (Shai et al.), with engineering science (Le Masson and Weil), with creativity (Taura and Nagai). They tend to underline their design logic in each discipline, and strong similarities between the different fields. For instance discovery in science (Shai et al.) and concept generation in more artistic domains (Taura and Nagai), or design of engineering objects and design in mathematics (Hatchuel et al.) tend to follow similar or complementary traits of design-recognition of the unknown, propagation of the concept based on available knowledge and generation of new concepts-even if the knowledge structures are apparently very different (mathematical models for Forcing in Hatchuel et al., engineering sciences for Infused Design in Shai et al., semantic models for concept generation in Taura and Nagai, ...). The models proposed and used contribute to uncover the deep convergence of reasoning used by engineers, scientists or artists.

\subsection{Theory-driven empirical research}

Many of the papers use empirical material (see Kroll, Taura and Nagai or Shai et al.; Le Masson and Weil refer rather to historical empirical cases). Nevertheless, they all put great emphasis on the research methods associated with formal design theories: some papers underline the importance of models' consistency (Hatchuel et al.), or they rely on formal models as comparative framework for other theories (Le Masson and Weil, Shai et al., Kroll), or use theories as an analytical tool to study methods (Kroll, Kazakçi, Le Masson and Weil, Shai et al.). In this perspective, empirical research is used more as an illustration (e.g., Kroll or Taura and Nagai). It is interesting to note that formal works can actually rely on multiple approaches. The formal models presented in these papers lead to insights that can be tested in empirical research: e.g., the role of duality for concept generation in science discovery (Shai et al.), the relationship between industrial growth, new products and the generativity of design theories
(Le Masson and Weil), the role of invariant ontology on generativity (Hatchuel et al.).

\section{Advances in design theory}

Overcoming the four difficulties, the papers contribute to design theory by building, discussing, strengthening, or analyzing specific formal models. They help to understand the ecology of design theories, how each theory relates to specific logics and specific models of knowledge, and how, despite apparent differences, the design theories tend to share strong common points, i.e. following Hatchuel et al., tend to follow a common ontology.

Reading the six papers of this special issue, one can distinguish three "moments". The first two papers, Le Masson and Weil and Kazakçi, help to clarify some historical roots and paradigms in the field of design theory. They explicate the relation between engineering science and the logic behind the historical variety of theories and methods in the field of engineering design (Le Masson and Weil) and the relation between constructivism and the paradigm of situated cognition (Kazakçi). Both papers pave the way to a better understanding of the ontology of design, which is the second moment of this special issue, mainly represented by the Hatchuel et al. paper. The third moment builds on the formal models today available to show how they help to analyze critical issues for designers: design and scientific discovery (Shai et al.), design and concept generation (Taura and Nagai) and design and the renewal of engineering rules (Kroll).

\subsection{Reconnecting to the roots}

In "Design theories as languages of the unknown: insights from the German roots of systematic design (1840-1960)", Pascal Le Masson and Benoit Weil study the historical development of theories and methods. They focus on the particular case of German systematic design at three historical moments-1840s and the industrial catch-up in Germany after the first industrial revolution; 1900s and the second industrial revolution; 1950s and the rationalization of intellectual work. Relying on the formal framework provided by $\mathrm{C}-\mathrm{K}$ theory, they show that (1) historically, design theories and methods did not originate from either purely formal research or from descriptive studies of designer's practices. They corresponded to specific rationalization of the design activity in historical context. (2) Contrary to engineering sciences, which model known objects, these theories are frameworks to guide the elaboration of still unknown objects with the help of available knowledge. They appear as more and more sophisticated languages of the unknown, whereas engineering models are 
languages of the known. These languages are progressively refined to reach new types of unknown. (3) These frameworks did not seek to cater for one-off innovation, but for the efficiency of design capacities. They analyze according to the types of new, partly unknown objects they help design (generative capacity) and the capacities required by their users (conjunctive capacity). The intention of these methods was to increase generative capacities while maintaining conjunctive capacity. Thus the paper works to overcome some issues in engineering design research: the difference with engineering science (language of the known vs. language of the unknown), the role of formal models to support the invention of methods (and the limits of descriptive models), and the ambition towards more generative theories. Creation of the language of the unknown and generativity emerge as basic traits of design theory.

In his paper entitled "on the imaginative constructivist nature of design", Akin Kazakçi discusses constructivism in design. He reminds us that constructivism is one of the paradigms that have a great influence on design theory: interactive constructivism, and more broadly situated cognition, analyzed how the interactive media can influence design; social constructivism analyzed the effects of communication and social conventions and negotiations on the integration of individual expertise into the design process. To discuss this invading paradigm, Kazakçi uses the formal roots of constructivism, namely Brouwer's intuitionism, which he analyzes with the lenses of formal design theory, $\mathrm{C}-\mathrm{K}$ theory. He shows that intuitionism presents interesting notions for building design logics in mathematics (see the introduction of "incomplete" objects by means of lawless sequences and free choices). This formal design perspective reveals a logic of "imaginative" constructivism by Brouwer's creative subject. While Brouwer's creative subject is usually interpreted as a learning model relying on the combination of known objects, it is shown that the creative subject can also alter the bottom-up, combinative construction with the introduction of unexpected elements in order to construct objects with surprising propertiesresulting in the expansion of the repertory of objects. Finally the paper suggests that in a design perspective, interactive constructivism should go beyond the analysis of shared representations to be able to include ruptures in reasoning and the "presentation" of new objects; and social constructivism should go beyond the understanding of trade-offs and negotiations to include the creation of new values and interests through imaginative propositions.

\subsection{Some elements of an ontology of design}

"Towards an ontology of design: lessons from $\mathrm{C}-\mathrm{K}$ theory and Forcing" by Armand Hatchuel, Benoit Weil and Pascal
Le Masson, aims at revealing an ontology of design by studying the similarities and differences between two of the most abstract formal theories of design, $\mathrm{C}-\mathrm{K}$ theory in engineering design and Forcing in Set theory in mathematics. Two specific features can characterize formal design theories: domain independence and generativity. $\mathrm{C}-\mathrm{K}$ theory is a good representative of the contemporary stage of abstraction and generativity in the field of engineering. As shown in the paper, the abstraction of Set theory makes that Forcing, a technique developed for the controlled invention of new models of sets, is a good representative of general design theories. The comparison reveals three common notions:

(1) knowledge expandability is present in each case but it also appears that design theories are led to distinguish variable structures (or designed ontologies) and invariant structures (explicitly unchanged by design, like the Zermelo-Fraenkel axiomatic in models of set generated by Forcing);

(2) knowledge "voids" are necessary for design, these are "independent structures" in existing knowledge, that are revealed when a proposition cannot be proved true or false with existing knowledge. The specific rationality of design is to "fill" the void to create a new desired thing;

(3) design needs generic processes for expansion, which include both the capacity to introduce new truths and revise the identity of objects and the capacity to re-order knowledge, to give new names and to preserve meaning.

\subsection{Design theories for understanding critical issues in design}

In "Design theory and conceptual design: contrasting functional decomposition and morphology with parameter analysis", Kroll analyses a method, Parameter Analysis, to deal with innovative "conceptual design". Whereas classical methods like functional analysis and morphological matrix (Zwicky 1969) tend to reuse existing design rules, with Parameter Analysis the designer focuses on the parameter that is considered as the most challenging issue of the design brief and this helps him to quickly identify the areas where the renewal of design rules is most needed. Moreover, it prescribes a loop for creating the new design rules, based on "creative synthesis" and "evaluation". Several cases illustrate how the method leads to renew design rules (Tilt-meter based on coupled pendulums, bilge pump and aerodynamic decelerators). Using $\mathrm{C}-\mathrm{K}$ theory the paper shows that Parameter Analysis helps designer to organize an intense relationship between $\mathrm{C}$ and $\mathrm{K}$, since 
each step of the Parameter Analysis process results in a $\mathrm{C}$ - and a K-expansion; by contrast functional analysis and morphology appear as a form of search process limited to available knowledge. Further, the paper discusses some efficiency criteria for a design process: whereas many design methods tend to favor finding one solution that minimizes the creation of knowledge, Parameter Analysis focuses on learning during the design process while being able to meet the specifications. This dual capacity of Parameter Analysis to both meet the target and favor efficient learning makes it a promising method for educating young designers and for strategic use in industrial design processes.

In "A Systematized Theory of Creative Concept Generation in Design: First-order and high-order", Toshiharu Taura and Yukari Nagai focus on the "concept generation" phase of a design process. In common view, this phase is said to be beyond the scope of "rational models", a phase of "creative synthesis" as opposed to more "analytical" ones. Relying on specific illustrations and rigorous concept mapping, the authors show that concept generation can be analyzed as an intersection of "abstract concepts"-in the terminology of General Design Theory. The paper shows that there are actually two contrasted types of concept generation, first order and higher order one, the first one relying on an intersection based on similarity recognition (in the intersection, the designers "follows" a thematic relation), whereas the second one relies on dissimilarity recognition. General Design Theory helps to describe both processes but the problem solving approach embedded in GDT describes thematic relations and fails to account for dissimilarity recognition processes. The paper calls for an extension of GDT based on the notion of dissimilarity in the pre-design phase.

In "Creativity and scientific discovery with infused design and its analysis with $\mathrm{C}-\mathrm{K}$ theory", Offer Shai, Yoram Reich, Armand Hatchuel and Eswaran Subrahmanian address one of the key challenges for a design theory: modeling scientific discovery. In his "models of thought" (Simon 1979) and more precisely in (Simon and Kulkarni 1989), Simon faced the same challenge. Shai et al. go beyond Simon's perspective to show how Infused Design helped to conceive a new force in physics, namely "face force"! Using C-K theory as an analytical tool, they show how scientific discovery relies on key aspects of design reasoning:

(1) There must be "holes" (the notion is similar to the "voids" in Hatchuel et al.) in knowledge. Further, infused design method is a powerful tool to identify these holes, by relying on strong knowledge structures across specific knowledge domains and by establishing, through duality relations, rigorous correspondences between these domains.
(2) "Filling holes" is based on knowledge, and infused design helps to acquire new knowledge by correspondences with multiple domains (the design of "face force" in trusses is based on correspondences with mechanism and electrical circuits).

(3) This knowledge propagation is done while preserving a consistency of the knowledge bases-and here again, infused design was instrumental in creating the "face force" that preserves the structures of knowledge domains.

Finally a design perspective on scientific discovery shows that the rigorous structure of scientific knowledge plays two critical roles in scientific discovery: it helps to identify "holes" and supports "consistent" expansions.

\section{Concluding remarks: design theory and the science of design}

This special issue brings to the reader a sample of works that illustrates the effort of a whole community, today, to renew its foundations. Following past (r)evolutions in design theory, it echoes trends in the new objects that have to be designed, trends in new forms of knowledge and knowledge production that have to be integrated in contemporary design processes and trends in other disciplines that are more and more linked to the design paradigm (like in past renewals, these design theories are linked to recent advances in many sciences-as diverse as mathematics, linguistics, engineering and even history).

Perhaps even more than in the past, the renewal of design theory should lead today to a body of sustainable, collective research. These papers show a good diversity and illustrate the constructive dialogue between multiple approaches. As a collection they help to make sense of the multiple formal models of design that exist today, and to integrate them in an ecology of theories. Finally, together they contribute to building a common language and create the capacity for fruitful discussions. As such, they hopefully provide a good basis for future advances on design theory and open the possibility of new forms of empirical research.

The renewal of design theory will help to build a powerful discipline, a unified body of knowledge that can engage with other disciplines on its own terms. External trends and paradigms will no longer threaten this unity and this unity will help in the discussion and expansion of these paradigms to the test of the design perspective. One can hope that the formal models of design theory will in due course spark dialogues with sociology, economics, engineering sciences, and cognition to provide new paradigms for the research in those fields. More generally, they offer 
good foundations for further formal work as well as for an open dialog with other disciplines. They pave the way to an "open program" to discuss design theory and art, design theory and management, design theory and politics, design theory and users, and design theory and information systems.

In the broadest sense, the renewal of design theory should help to understand and support contemporary forms of collective action. The effort towards a clear design paradigm contributes to improving dialogue between the professions, recognizing their deep similarities. But looking beyond these professional developments, we realize that our societies expect "innovative design" on major challenges: in health, in smart cities, in sustainable energy, in smart mobility, in the autonomy of elderly people, in housing for everybody or in food... Recent advances in design theory might help to invent new forms of design action to address all these issues. They open the possibility to invent new methods, new organizations, and new forms of designerly collaborations inside and between organizations. These theories could provide the basic corpus and language to educate the designers of tomorrow in the logic of creation. And we need them as basic intellectual elements for life in contemporary societies that are entering the post-decisional paradigm - the design paradigm.

\section{References}

Alexander C (1964) Notes on the synthesis of form, 15th printing, 1999th edn. Harvard University Press, Cambridge

Braha D, Reich Y (2003) Topological structures for modelling engineering design processes. Res Eng Des 14(4):185-199

Cross N (ed) (1984) Developments in design methodology. Wiley, New York

Dorst K (2006) Design problems and design paradoxes. Des Issues 22(3):4-17

Dorst K, Vermaas PE (2005) John Gero's function-behaviourstructure model of designing: a critical analysis. Res Eng Des 16(1-2):17-26

Ehrlenspiel K (1995) Intégrierte Produktentwicklung. Methoden für Prozessorganisation, Produkterstellung und Konstruktion. Carl Hanser Verlag, München
Finger S, Dixon JR (1989) A review of research in mechanical engineering design. Res Eng Des 1:51-67 (part I) and 121-137 (part II)

Gero JS (1990) Design prototypes: a knowledge representation schema for design. AI Mag 11(4):26-36

Hatchuel A (2002) Towards design theory and expandable rationality: the unfinished program of Herbert Simon. J Manag Gov 5(3-4):260-273

Hatchuel A, Weil B (2009) C-K design theory: an advanced formulation. Res Eng Des 19(4):181-192

Heymann M (2005) "Kunst" und Wissenchsaft in der Technik des 20. Jahrhunderts. Zur Geschichte der Konstruktionswissenschaft. Chronos Verlag, Zürich

Hubka V, Eder WE (1988) Theory of technical systems. A total concept theory for engineering design. Springer, Berlin

Jones JC, Thornley DG (eds) (1963) Conference on design methods. In: papers presented at the conference on systematic and intuitive methods in engineering, industrial design, architecture and communications, London, September 1962. Pergamon, Oxford

Konda S, Monarch IA, Sargent P, Subrahmanian E (1992) Shared memory in design: a unifying theme for research and practice. Res Eng Des 4(1):23-42

Reich Y (1995) A critical review of general design theory. Res Eng Des 7:1-18

Shai O, Reich Y (2004) Infused design. I. Theory. Res Eng Des 15(2):93-107

Simon HA (1969) The sciences of the artificial. MIT Press, Cambridge

Simon HA (ed) (1979) Models of thought, vol 1. Yale University Press, New Haven

Simon HA, Kulkarni D (1989) The processes of scientific discovery: the strategy of experimentation. In: Simon HA (ed) Models of thought, vol 2. Yale University Press, New Haven, pp 356-382

Subrahmanian E, Sriram R, Herder PM, Christians HH, Schneider R (2004) Role of empirical studies in understanding and supporting design. Delft University Press, Delft

Suh NP (1990) Principles of design. Oxford University Press, New York

van Casteren A, Sellers WI, Thorpe SKS, Coward S, Crompton RH, Myatt JP, Ennos AR (2012) Nest-building orangutans demonstrate engineering know-how to produce safe, comfortable beds. Proc Natl Acad Sci 109(18):6873-6877

Yoshikawa H (1981) General design theory and a CAD System. In: Sata T, Warman E (eds) Man-machine communication in CAD/ CAM. In: Proceedings of the IFIP WG5.2-5.3 Working conference 1980 (Tokyo). North-Holland, Amsterdam, pp 35-57

Zwicky F (1969) Discovery, invention, research-through the morphological approach. The Macmillian Company, Toronto 